\title{
Излучательная рекомбинация на ионно-индуцированных дефектах в тонких пленках твердых растворов $\mathrm{Cu}(\mathrm{In}, \mathrm{Ga}) \mathrm{Se}_{2}$
}

\author{
(C) О.М. Бородавченко ${ }^{1}$, В.Д. Живулько ${ }^{1}$, А.В. Мудрый ${ }^{1}$, М.В. Якушев ${ }^{2,3}$, И.А. Могильников ${ }^{2}$ \\ ${ }^{1}$ Научно-практический центр Национальной академии наук Беларуси по материаловедению, \\ 220072 Минск, Беларусь \\ ${ }^{2}$ Институт физики металлов им. М.Н. Михеева, Уральское отделение Российской академии наук, \\ 620108 Екатеринбург, Россия \\ ${ }^{3}$ Уральский федеральный университет, \\ 620002 Екатеринбург, Россия \\ E-mail: riayue@yandex.ru
}

Поступила в Редакцию 7 октября 2020 г.

В окончательной редакции 14 октября 2020 г.

Принята к публикации 14 октября 2020 г.

В тонких пленках твердых растворов $\mathrm{Cu}(\mathrm{In}, \mathrm{Ga}) \mathrm{Se}_{2}$ изучены радиационно-индуцированные эффекты после имплантации ионами водорода с энергией 2.5, 5 и 10 кэВ, дозой $\sim 3 \cdot 10^{15} \mathrm{~cm}^{-2}$. Сравнительный анализ оптических характеристик неимплантированных и имплантированных водородом тонких пленок $\mathrm{Cu}(\mathrm{In}, \mathrm{Ga}) \mathrm{Se}_{2}$ был проведен на основе измеренных спектров фотолюминесценции и спектров возбуждения люминесценции, снятых при температуре жидкого гелия, $\sim 4.2 \mathrm{~K}$. Ширина запрещенной зоны твердых растворов $\mathrm{Cu}(\mathrm{In}, \mathrm{Ga}) \mathrm{Se}_{2}$, определенная по данным математической обработки спектров возбуждения люминесценции, составила $\sim 1.171$ эВ. В спектрах фотолюминесценции неимплантированных и имплантированных водородом пленок $\mathrm{Cu}(\mathrm{In}, \mathrm{Ga}) \mathrm{Se}_{2}$ обнаружена интенсивная полоса с максимумом при $\sim 1.089$ эВ, обусловленная рекомбинацией свободных электронов с дырками, локализованными в хвостах валентной зоны. Установлено, что появление в спектрах фотолюминесценции широких полос с максимумами в области энергий $\sim 0.92$ и $\sim 0.77$ эВ обусловлено излучательной рекомбинацией неравновесных носителей заряда на глубоких энергетических уровнях ионно-индуцированных дефектов акцепторного типа, образующихся в запрещенной зоне твердых растворов $\mathrm{Cu}(\mathrm{In}, \mathrm{Ga}) \mathrm{Se}_{2}$. Обсуждаются условия возникновения эффекта ионной пассивации оборванных электронных связей на поверхности и в объеме поликристаллических пленок $\mathrm{Cu}(\mathrm{In}, \mathrm{Ga}) \mathrm{Se}_{2}$, а также природа точечных дефектов структуры и механизмы излучательной рекомбинации.

Ключевые слова: твердые растворы $\mathrm{Cu}(\mathrm{In}, \mathrm{Ga}) \mathrm{Se}_{2}$, фотолюминесценция, ионы водорода, дефекты, энергетические уровни, ширина запрещенной зоны.

DOI: 10.21883/FTP.2021.02.50497.9532

\section{1. Введение}

На современном этапе развития энергетики вклад полупроводниковой фотовольтаики по отношению к другим возобновляемым источникам энергии существенно увеличился [1,2]. При этом одними из наиболее востребованных полупроводниковых материалов являются твердые растворы $\mathrm{Cu}(\mathrm{In}, \mathrm{Ga}) \mathrm{Se}_{2}$ со структурой халькопирита [2-4]. Прямозонная энергетическая структура и высокий коэффициент поглощения, $\alpha \sim 10^{5} \mathrm{~cm}^{-1}$, твердых растворов $\mathrm{Cu}(\mathrm{In}, \mathrm{Ga}) \mathrm{Se}_{2}$ способствуют созданию солнечных элементов на основе тонких пленок, толщиной 1-3 мкм [1-4]. В дополнение к этому возможность подбора элементного состава твердых растворов $\mathrm{CuIn}_{1-x} \mathrm{Ga}_{x} \mathrm{Se}_{2}$ в диапазоне $x=[\mathrm{Ga}] /([\mathrm{Ga}]+[\mathrm{In}]) \approx 0.20-0.45$ позволяет оптимально приблизить значение ширины прямой запрещенной зоны $E_{g} \approx 1.1-1.3$ эВ к максимуму спектрального распределения солнечного излучения и создавать высокоэффективные тонкопленочные солнечные элементы на основе этого материала [5-7]. В настоящее время коэффициент полезного действия (кпд) солнечных батарей большого размера и лабораторных солнеч- ных элементов на основе прямозонных полупроводников $\mathrm{Cu}(\mathrm{In}, \mathrm{Ga}) \mathrm{Se}_{2}, \mathrm{Cu}(\mathrm{In}, \mathrm{Ga})(\mathrm{S}, \mathrm{Se})_{2}$ увеличился до $18.0-22.6 \%[6,7]$ и $\sim 23.35 \%$ [8] соответственно, что сопоставимо со значениями кпд для солнечных элементов на основе кремния [2]. По прогнозу специалистов, разрабатывающих полупроводниковые фотопреобразователи солнечной энергии, $\mathrm{Cu}(\mathrm{In}, \mathrm{Ga}) \mathrm{Se}_{2}$ является одним из наиболее перспективных и дешевых материалов для практического применения. Проведенные исследования показали, что основные параметры (напряжение холостого хода, ток короткого замыкания, фактор заполнения вольт-амперной характеристики, кпд) солнечных элементов на основе $\mathrm{Cu}(\mathrm{In}, \mathrm{Ga}) \mathrm{Se}_{2}$ обладают повышенной радиационной стойкостью по сравнению с аналогичными параметрами солнечных элементов на основе $\mathrm{Si}, \mathrm{CdTe}$, GaAs, InP и др. [9,10]. Установлено, что облучение поликристаллических тонких пленок $\mathrm{Cu}(\mathrm{In}, \mathrm{Ga}) \mathrm{Se}_{2}$ низкоэнергетическими ионами водорода наряду с эффектом образования радиационно-индуцированных дефектов приводит к пассивации оборванных электронных связей на поверхности и границах раздела кристаллических зерен, тем самым улучшая некоторые физические 
характеристики материала $[11,12]$. Основываясь на этом, можно считать, что твердые растворы $\mathrm{Cu}(\mathrm{In}, \mathrm{Ga}) \mathrm{Se}_{2}$ со структурой халькопирита являются перспективными материалами для создания тонкопленочных солнечных элементов, пригодных для эксплуатации в условиях воздействия проникающей радиации на околоземных орбитах, в частности на космических кораблях и спутниках. Однако процессы радиационного дефектообразования в твердых растворах $\mathrm{Cu}(\mathrm{In}, \mathrm{Ga}) \mathrm{Se}_{2}$ все еще остаются мало изученными, что препятствует дальнейшему развитию технологии создания радиационно стойких солнечных элементов. В настоящей работе приведены новые данные о природе радиационно-индуцированных дефектов при имплантации водорода и их влиянии на изменение оптических свойств тонких пленок твердых растворов $\mathrm{Cu}(\mathrm{In}, \mathrm{Ga}) \mathrm{Se}_{2}$ в зависимости от условий облучения.

\section{2. Методика эксперимента}

Исследования проводились на поликристаллических тонких пленках твердых растворов $\mathrm{Cu}(\mathrm{In}, \mathrm{Ga}) \mathrm{Se}_{2}$ (CIGSe), толщиной $\sim(1.4-1.6)$ мкм, осажденных на натрийсодержащие стеклянные подложки методом испарения исходных высокочистых элементов $\mathrm{Cu}, \mathrm{In}, \mathrm{Ga}$ и $\mathrm{Se}$ в многостадийном процессе [12,13]. Пленки облучались низкоэнергетическими ионами водорода $\mathrm{H}^{+}$с энергиями $\sim 2.5,5$ и 10 кэВ, дозой $\sim 3 \cdot 10^{15} \mathrm{~cm}^{-2}$ в ускорителе протонов с магнитным сепаратором. Плотность тока ионов $\mathrm{H}^{+}$составляла $\sim 5 \mathrm{M \kappa} \mathrm{A} / \mathrm{cm}^{2}$. Рентгеноструктурный анализ твердых растворов CIGSe проводился на дифрактометре ДРОН-3М в монохроматическом $\mathrm{Cu} K_{\alpha}$-излучении, длина волны $\sim 1.5604 \AA$. Дифрактограммы регистрировались в интервале углов дифракции $2 \theta \approx 15-75^{\circ}$ в режиме сканирования с шагом $0.02^{\circ}$ и временем накопления сигнала 3 с. Структура поверхности и поперечных сколов тонких пленок анализировалась с использованием сканирующего электронного микроскопа (CЭM) Tescan Mira 3GMU („Тescan“, Чехия). Рентгеноспектральный микроанализатор с энергетической дисперсией на основе кремниевого детектора SDD X-max („Oxford Instruments“, Великобритания), встроенный в СЭМ, позволял проводить измерения элементного состава твердых растворов CIGSe. Регистрация спектров фотолюминесценции (ФЛ) и спектров возбуждения люминесценции (СВЛ) проводилась с использованием монохроматора МДР-23У, оснащенного дифракционной решеткой 600 штрихов/мм (обратная линейная дисперсия $\sim 26 \AA /$ М). При регистрации спектров ФЛ использовали твердотельные лазеры с длиной волны излучения 532 и 405 нм. Плотность мощности лазерного возбуждения варьировали нейтральными светофильтрами в диапазоне $\sim(0.1-8.0) \mathrm{BT} / \mathrm{cm}^{2}$. При регистрации СВЛ в качестве источника возбуждения использовалась вольфрамовая лампа накаливания мощностью $\sim 200 \mathrm{BT}$, излучение которой пропускалось через монохроматор МДР-12, оснащенный дифракционной решеткой 600 штрихов/мм (обратная линейная дисперсия $\sim 52 \AA / \mathrm{MM}$ ). Модуляция светового излучения от вольфрамовой лампы и лазеров осуществлялась на частоте $\sim 20$ Гц. В качестве детектора оптических сигналов использовался $p-i-n$-фотодиод из InGaAs („Наmamatsu“, Япония) типа G10899-03K, работающий в спектральном диапазоне 0.5-1.7 мкм. Спектры ФЛ и СВЛ корректировали с учетом спектрального распределения интенсивности излучения вольфрамовой лампы, аппаратной функции монохроматора и спектральной чувствительности детектора излучения. Запись спектров ФЛ и СВЛ проводилась на основе метода синхронного фазового детектирования с аналогоцифровым преобразованием электрических сигналов в цифровой код и их автоматической регистрацией в файл компьютера.

\section{3. Результаты и обсуждение}

Исследования структуры поверхности и поперечного скола тонких пленок CIGSe с использованием сканирующего электронного микроскопа показали, что пленки имеют поликристаллическую структуру с размером отдельных зерен от 0.4 до 1.3 мкм с четкими очертаниями их граней и границ. Изображения структуры поверхности и поперечных сколов тонких пленок CIGSe свидетельствуют о плотной упаковке зерен, малой пористости и высокой адгезии к стеклянной подложке.

На рис. 1 приведена дифрактограмма исходной (неимплантированной) тонкой пленки твердого раствора CIGSe в полулогарифмическом масштабе. Дифракционные рефлексы 112, 220/204, 312/116, 332/316 соответствуют фазе халькопирита [14]. Соотношение интенсивностей рефлексов 112/220,204 составило $~ 150$. Высокая интенсивность основного рефлекса 112 указывает на преимущественную ориентацию зерен в данном кристаллографическом направлении, в то время как

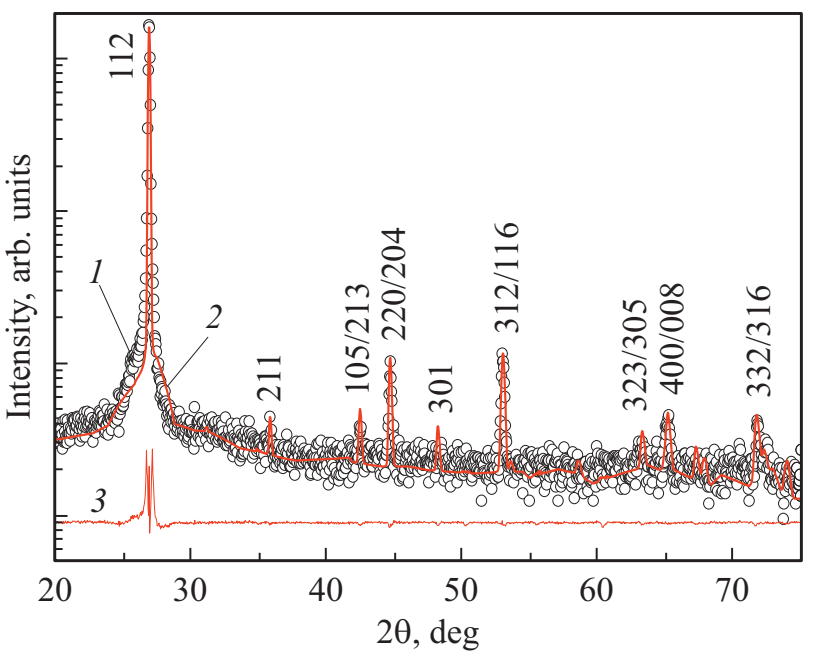

Рис. 1. Дифрактограмма неимплантированной тонкой пленки $\mathrm{Cu}(\mathrm{In}, \mathrm{Ga}) \mathrm{Se}_{2}: 1$ - эксперимент, 2 - подгоночная кривая, 3 - разностная кривая. 
малая полуширина всех рефлексов отражения свидетельствует о высоком качестве структуры тонкой пленки CIGSe. C применением компьютерного программного обеспечения FullProf был проведен полнопрофильный анализ дифрактограммы. Экспериментально полученный контур рефлексов отражения был аппроксимирован функцией Pseudo-Voigt и обработан методом Ритвельда, что позволило определить параметры элементарной ячейки. Хорошее соответствие эксперимента и расчета наблюдается при численных значениях параметров элементарной ячейки $a \approx 5.738 \AA$ и $c \approx 11.45 \AA$, что проиллюстрировано разностной кривой в нижней части рис. 1. Исследования показали, что имплантация тонких пленок твердых растворов CIGSe не меняет углового положения дифракционных рефлексов, их полуширины и относительного соотношения интенсивностей. Это может быть объяснено небольшой глубиной пробега ионов водорода и малой концентрацией ионно-индуцированных дефектов. В соответствии с оценками по программе TRIM средний пробег ионов водорода в тонких пленках CIGSe составлял $\sim(35-100)$ нм в диапазоне энергий 2.5-10 кэВ, а рентгеноструктурный анализ проводился по всей толщине пленки 1.6 мкм $[15,16]$. Сравнение параметров элементарной ячейки $a$ и $c$, определенных в данной работе, с аналогичными известными значениями для твердых растворов $\mathrm{CuIn}_{1-x} \mathrm{Ga}_{x} \mathrm{Se}_{2}$ в диапазоне составов с $0 \leq x \leq 1$ позволило оценить состав исследованных нами пленок как соответствующий $x \approx 0.21-0.22[17,18]$.

На рис. 2 в качестве примера в полулогарифмическом масштабе представлена зависимость спектров ФЛ неимплантированной тонкой пленки CIGSe от плотности мощности лазерного излучения, снятая при непосредственном погружении образца в жидкий гелий $(\sim 4.2 \mathrm{~K})$ с использованием специального оптического криостата. Длина волны возбуждающего лазерного излучения составляла $\sim 405$ нм. В спектре ФЛ присутствует ин-

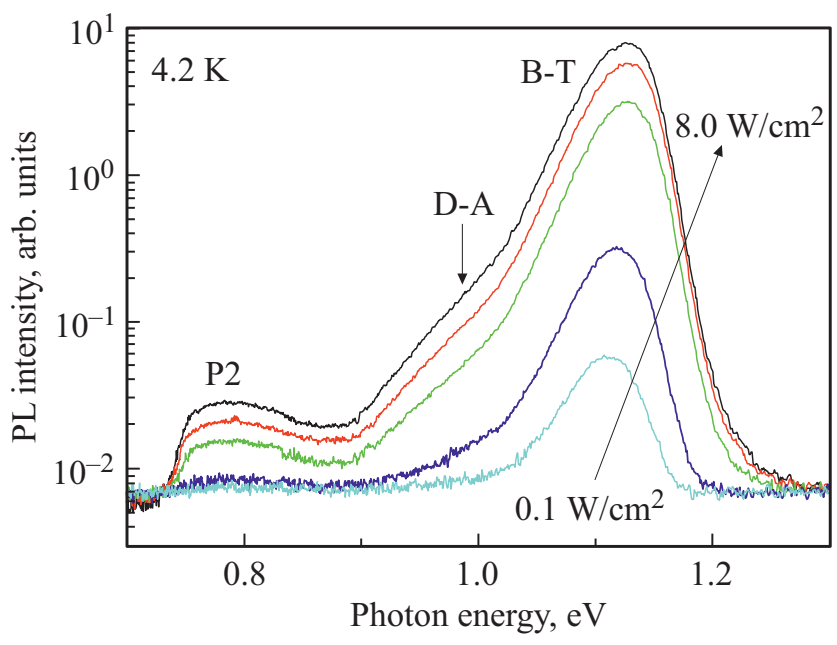

Pис. 2. Зависимость спектров фотолюминесценции (PL) неимплантированной тонкой пленки $\mathrm{Cu}(\mathrm{In}, \mathrm{Ga}) \mathrm{Se}_{2}$ от плотности мощности лазерного возбуждения с длиной волны $\sim 405$ нм.

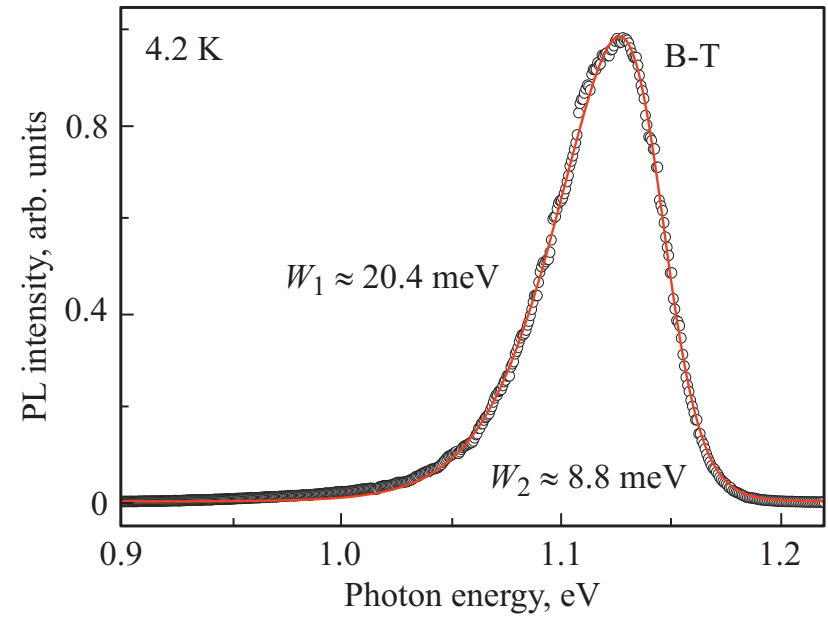

Pис. 3. Спектр фотолюминесценции (PL) неимплантированной тонкой пленки $\mathrm{Cu}(\mathrm{In}, \mathrm{Ga}) \mathrm{Se}_{2}$, снятый при плотности мощности лазерного возбуждения $\sim 0.8 \mathrm{BT} / \mathrm{cm}^{2}$.

тенсивная полоса близкраевой люминесценции В-Т с максимумом при $\sim 1.125$ эВ. С увеличением плотности мощности возбуждения полоса смещается в область высоких энергий с коэффициентом $j$-shift $\sim 10.2$ мэВ при изменении плотности мощности возбуждения на один порядок. Полоса В-Т может быть отнесена к излучательной рекомбинации свободных электронов с дырками на энергетических уровнях дефектов акцепторного типа, находящихся под сильным влиянием флуктуаций локального потенциала в кристаллической решетке твердых растворов CIGSe („хвосты“ плотности электронных состояний вблизи валентной зоны) $[19,20]$. Полоса D-A с максимумом при $\sim 1.0$ эВ относится к излучательной рекомбинации на ростовых дефектах донорного и акцепторного типов. Также из рис. 2 видно, что в низкоэнергетической области спектра ФЛ присутствует слабоинтенсивная полоса Р2 с максимумом при $\sim 0.77$ эВ. Предполагается, что она обусловлена оптическими переходами электронов из зоны проводимости на глубокие акцепторные уровни дефектов, образованных из-за отклонения химического состава твердых растворов CIGSe от стехиометрии при осаждении тонких пленок на стеклянные подложки при высоких температурах, $\sim(530-560)^{\circ} \mathrm{C}$.

В качестве примера на рис. 3 представлена математическая обработка контура полосы В-T неимплантированной тонкой пленки твердого раствора CIGSe. Обработка контура полосы проводилась с помощью следующей формулы [21]:

$$
\begin{aligned}
I(h v)= & A\left[1+\exp \left(-\frac{\left(h v-E_{1}\right)}{W_{1}}\right)\right]^{-1} \\
& \times\left\{1-\left[1+\exp \left(-\frac{\left(h v-E_{2}\right)}{W_{2}}\right)\right]^{-1}\right\},
\end{aligned}
$$

где $A, E_{1}, E_{2}, W_{1}$ и $W_{2}$ являются подгоночными параметрами. Параметры $E_{1}$ и $W_{1}$ описывают низкоэнерге- 


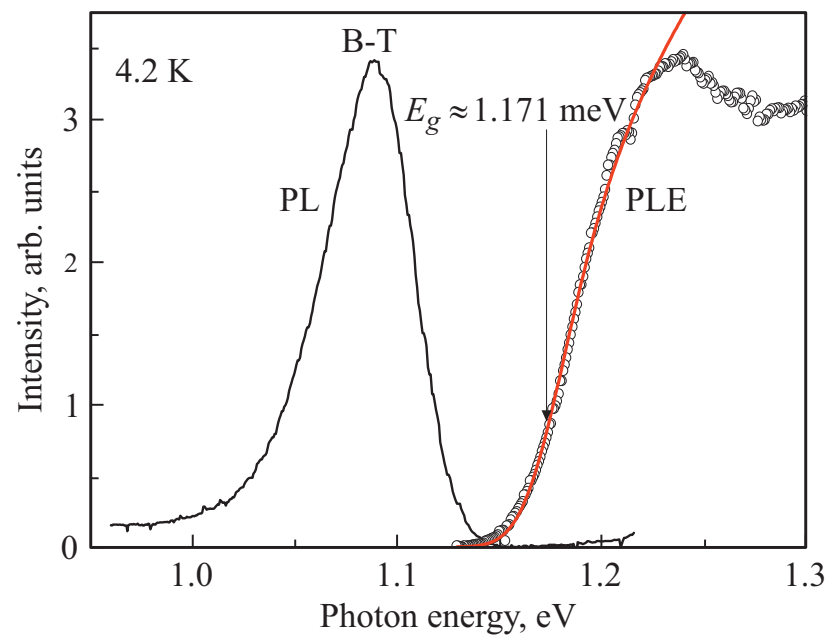

Рис. 4. Спектры фотолюминесценции (PL) и спектры возбуждения люминесценции (PLE) неимплантированной тонкой пленки $\mathrm{Cu}(\mathrm{In}, \mathrm{Ga}) \mathrm{Se}_{2}$.

тический контур полосы, а $E_{2}$ и $W_{2}-$ высокоэнергетический. Полученное значение энергии $W_{1} \approx 20.4$ мэВ соответствует средней глубине флуктуаций потенциала в кристаллической решетке тонких пленок CIGSe. Значение энергии $W_{2} \approx 8.8$ мэВ соответствует более резкому спаду интенсивности в высокоэнергетической области полосы В-Т.

На рис. 4 представлены спектры ФЛ и СВЛ неимплантированной тонкой пленки CIGSe, снятые при температуре $\sim 4.2 \mathrm{~K}$ с малой плотностью мощности возбуждения, $\sim 0.001 \mathrm{BT} / \mathrm{cm}^{2}$. Запись СВЛ осуществлялась при энергии детектирования, соответствующей максимуму полосы ФЛ $\sim 1.089$ эВ. Эти эксперименты позволили определить ширину запрещенной зоны $E_{g}$ твердых растворов CIGSe.

Математическая обработка СВЛ была проведена с использованием следующей зависимости [20]:

$$
\begin{aligned}
\alpha \propto & \int_{0}^{\infty} \frac{1}{\sigma \sqrt{2 \pi}} \exp \left(-\frac{1}{2}\left(\frac{E_{g}-E_{g, \text { mean }}}{\sigma}\right)^{2}\right) \\
& \times\left(\frac{\sqrt{\hbar \omega-E_{g}}}{\hbar \omega}\right) d E_{g},
\end{aligned}
$$

где $\alpha-$ коэффициент поглощения, $\sigma$ - стандартное отклонение, $E_{g \text {,mean }}-$ среднее значение ширины запрещенной зоны, $\hbar \omega-$ энергия фотонов. Оцененное значение ширины запрещенной зоны $E_{g}$ для неимплантированной и имплантированной водородом тонких пленок CIGSe оказалось одинаковым и составило $\sim(1.171 \pm 0.005)$ эВ.

На рис. 5 представлены спектры ФЛ тонких пленок твердых растворов CIGSe, имплантированных ионами водорода $\mathrm{H}^{+}$с энергией в диапазоне 2.5-10 кэВ, дозой $\sim 3 \cdot 10^{15} \mathrm{~cm}^{-2}$, снятые при температуре $\sim 4.2 \mathrm{~K}$ и при возбуждении лазерным излучением на различных длинах волн. Из рис. 5 видно, что спектры ФЛ тонких пленок CIGSe характеризуются наличием высокоинтенсивной полосы близкраевой люминесценции В-Т с максимумом при $\sim 1.125$ эВ и полушириной $\sim 60$ мэВ. Облучение пленок CIGSe приводит к незначительному увеличению полуширины полосы В-Т и ее смещению в область низких энергий по отношению к краю фундаментального поглощения с увеличением энергии ионов водорода от 2.5 до 10 кэВ. Это может быть следствием увеличения флуктуаций потенциала кристаллической решетки из-за образования в твердых растворах CIGSe радиационно-индуцированных дефектов и соответственно усиления их влияния на энергетические состояния центров излучательной рекомбинации, ответственных за появление полосы В-T.

На рис. 5, $а$ в спектрах ФЛ, снятых с использованием лазера с длиной волны $\sim 405$ нм, отчетливо видна деградация полосы близкраевой люминесценции В-T с
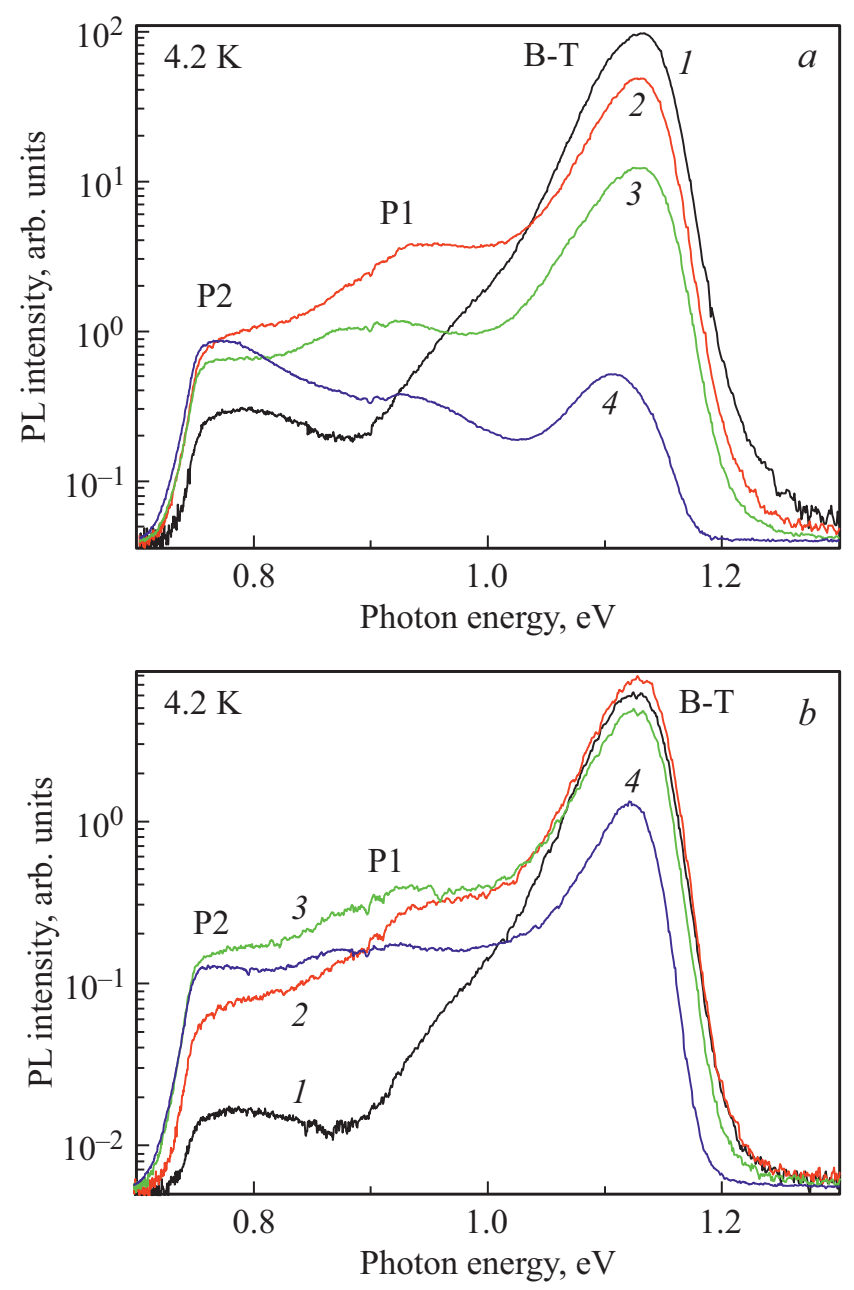

Рис. 5. Спектры фотолюминесценции (PL) тонких пленок $\mathrm{Cu}(\mathrm{In}, \mathrm{Ga}) \mathrm{Se}_{2}$, неимплантированной $(1)$ и имплантированных ионами водорода с энергией 2.5 (2), 5.0 (3), 10 кэВ (4). Возбуждение излучением лазера с длиной волны $\sim 405$ нм $(a)$ и $\sim 532$ нм $(b)$. 
увеличением энергии имплантируемых ионов водорода. На рис. 5, $b$ в спектрах ФЛ, снятых с использованием лазера с длиной волны $\sim 532$ нм, наблюдается заметное увеличение интенсивности полосы близкраевой люминесценции В-Т и ее небольшое смещение в область высоких энергий при имплантации тонких пленок CIGSe ионами водорода с энергией $\sim 2.5$ кэВ. Увеличение энергии имплантируемых ионов водорода до 5 кэВ незначительно уменьшает интенсивность полосы В-T. Более сильное уменьшение интенсивности полосы В-T и ее смещение в низкоэнергетическую область спектра наблюдается в случае, когда энергия ионов водорода составляет $\sim 10$ кэВ. При этом высокоэнергетический контур полосы В-Т является более резким (рис. 5, $b$ ) по сравнению с контуром этой полосы, зарегистрированной при возбуждении тонких пленок CIGSe лазерным излучением на длине волны $\sim 405$ нм (рис. $5, a$ ). Наблюдаемые в спектрах относительные изменения являются подтверждением наличия эффекта пассивации электронных состояний внедренными ионами водорода на поверхности и в объеме поликристаллических пленок на границах раздела зерен или дефектах структуры. Это обусловлено большей глубиной проникновения, $\sim 100$ нм, лазерного излучения на длине волны $\sim 532$ нм по сравнению с глубиной проникновения $\sim 30$ нм на длине волны $\sim 405 \mathrm{нм}$. При этом пробег ионов водорода и соответствующее распределение ионно-индуцированных дефектов по толщине пленки составляли $\sim(35-100)$ нм в зависимости от их энергии $[15,16]$.

Кроме изменения интенсивности, спектрального положения и полуширины полосы близкраевой люминесценции В-T, наиболее важным результатом имплантации тонких пленок CIGSe ионами водорода является появление в спектрах ФЛ полос в низкоэнергетической области. На рис. 5 полосы обозначены как $\mathrm{P} 1(\sim 0.92$ эВ $)$ и $\mathrm{P} 2(\sim 0.77$ эВ). Рост интенсивности этих полос при увеличении энергии облучения дает основания предположить, что они обусловлены излучательной рекомбинацией на радиационно-индуцированных дефектах в CIGSe. Процесс радиационного дефектообразования оказывает непосредственное влияние и на изменение относительной интенсивности полосы близкраевой люминесценции В-Т из-за образования новых центров излучательной рекомбинации, приводящих к перераспределению каналов рекомбинации неравновесных носителей заряда.

На рис. 6 в полулогарифмическом масштабе приведены спектры ФЛ тонких пленок CIGSe, имплантированных ионами водорода с энергией 10 кэВ, дозой $3 \cdot 10^{15} \mathrm{~cm}^{-2}$, снятые при возбуждении неравновесных носителей заряда лазерным излучением с длинами волн 405 и 532 нм в диапазоне плотностей мощности $\sim(0.1-8.0) \mathrm{BT} / \mathrm{cm}^{2}$.

Сравнительный анализ относительных интенсивностей полос В-Т, Р1 и Р2, представленных на рис. 6, $a b$, подтверждает тот факт, что образование радиационноиндуцированных дефектов в пленках CIGSe влияет на
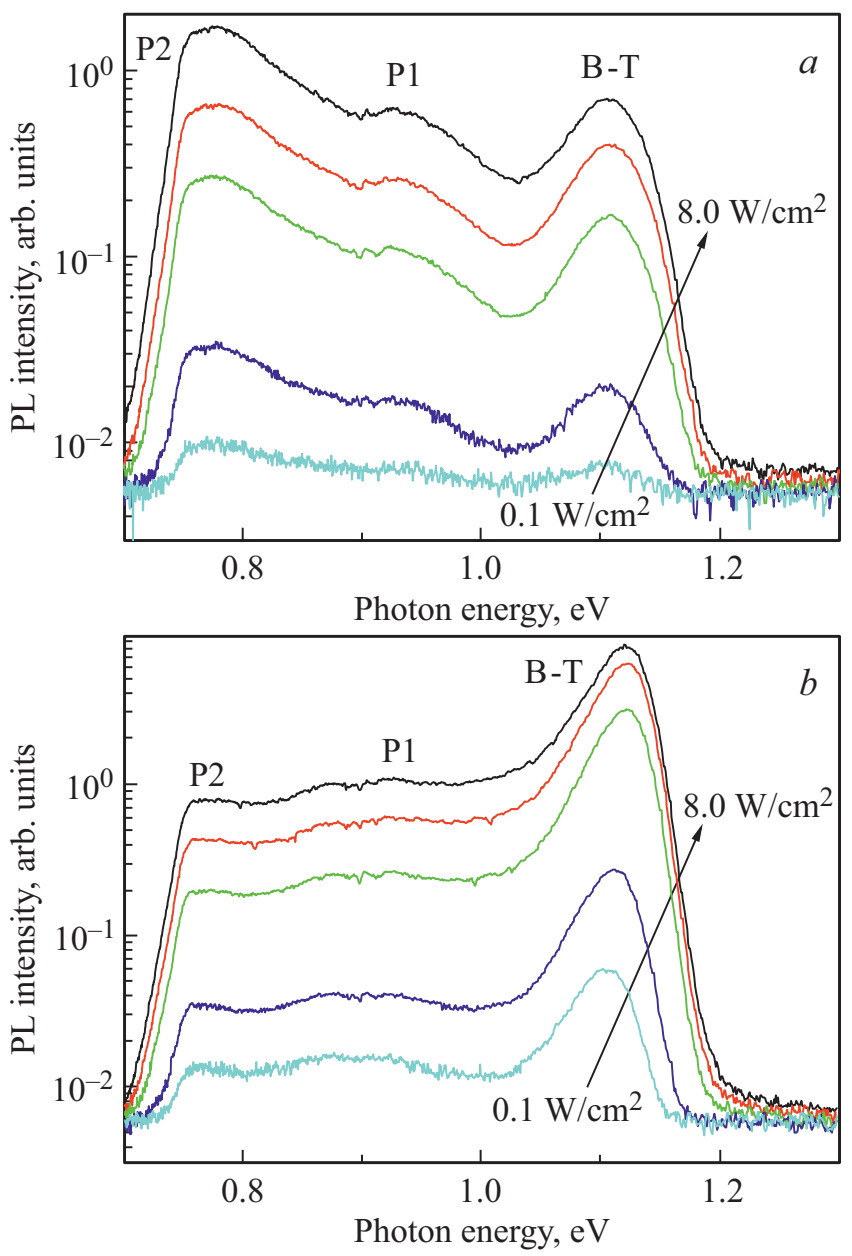

Рис. 6. Зависимость спектров фотолюминесценции (PL) тонких пленок $\mathrm{Cu}(\mathrm{In}, \mathrm{Ga}) \mathrm{Se}_{2}$, имплантированных ионами водорода c энергией 10 кэВ, от плотности мощности лазерного возбуждения с длиной волны $\sim 405$ нм $(a)$ и $\sim 532$ нм $(b)$.

перераспределение каналов излучательной рекомбинации. Из рис. 6, $a$ видно, что при наличии излучательной рекомбинации на ионно-индуцированных дефектах относительная интенсивность полосы В-Т близкраевой люминесценции уменьшается. Спектры ФЛ, полученные с использованием двух лазеров, отличаются заметным перераспределением интенсивностей полосы близкраевой люминесценции В-Т и полос, обусловленных рекомбинацией на радиационно-индуцированных дефектах P1 и Р2. Из рис. 6, $a$ видно, что интенсивность полосы P2 в спектре тонкой пленки CIGSe, снятой при возбуждении неравновесных носителей заряда лазером с длиной волны $405 \mathrm{HM}$, превосходит интенсивность полосы В-Т. Однако подобный эффект не наблюдается в случае использования излучения с длиной волны 532 нм, имеющего большую глубину проникновения. Этот эффект может быть объяснен различной глубиной проникновения лазерного излучения для длин волн $\sim 405, \sim 532$ нм и различным характером распределения радиационно-индуцированных дефектов, ответственных 
за появление в спектрах ФЛ полос В-Т, Р1 и Р2, по толщине пленок. Эксперименты показали, что при увеличении плотности мощности возбуждения энергетическое положение полос Р1 и Р2 не изменяется, свидетельствуя о рекомбинации на глубоких энергетических уровнях радиационно-индуцированных дефектов. Анализ энергетического положения полосы В-T в спектрах ФЛ, зарегистрированных с использованием лазеров с длинами волн $\sim 405$ и $\sim 532 \mathrm{Hм} \mathrm{в} \mathrm{зависимости} \mathrm{от}$ плотности мощности лазерного излучения, показал, что численное значение коэффициента $j$-shift составляет $\sim 3.5$ и 8.4 мэВ на порядок изменения плотности мощности соответственно. Необходимо отметить, что для необлученных тонких пленок CIGSe численное значение коэффициента $j$-shift составляло $\sim 10.2$ мэВ.

Ионно-внедренный водород с энергией в несколько кэВ создает в кристаллической решетке CIGSe первичные радиационные дефекты, межузельные атомы и вакансии. B ZnSe, который является бинарным аналогом $\mathrm{CuInSe}_{2}$, межузельные атомы, созданные в результате облучения электронами с энергиями порядка МэВ, остаются подвижными при температуре $1.5 \mathrm{~K}$ [21]. Поэтому мы можем предположить, что значительная часть ионноиндуцированных первичных дефектов рекомбинирует между собой в течение процесса обучения и сразу после этого. Такая рекомбинация сопровождается формированием устойчивых вторичных дефектов и дефектных комплексов [22]. Наиболее вероятными вторичными дефектами в CIGSe представляются дефекты замещения например, атомы In и $\mathrm{Ga}$ в положении $\mathrm{Cu}\left(\mathrm{In}_{\mathrm{Cu}}, \mathrm{Ga}_{\mathrm{Cu}}\right)$ и атомы $\mathrm{Cu}$ в положении индия In $\left(\mathrm{Cu}_{\mathrm{In}}\right)$, дивакансии. Следует отметить, что возможно формирование вторичных дефектов, содержащих внедренный водород: например, атом водорода в вакансии меди $\left(\mathrm{H}_{\mathrm{Cu}}\right)$. Такое замещение уменышает концентрацию основных акцепторов CIGSe, пассивируя их. В случае $\mathrm{CuInSe}_{2} p$-типа проводимости облучение водородом меняет проводимость на $n$-тип [23]. В случае же CIGSe, который не может быть $n$-типа проводимости, должно происходить уменьшение степени компенсации материала, что и проявляется в значительном уменьшении коэффициента $j$-shift. Атомарный водород быстро диффундирует на значительные глубины $[24,25]$ и пассивирует там вакансии меди. Однако наиболее значительные его концентрации находятся в слое, в который был внедрен водород. Для энергий ионов водорода 2.5, 5 и 10 кэВ максимумы концентрации водорода, рассчитанные с помощью программы TRIM [26], находятся на глубине 32, 45 и $87 \mathrm{HM}$ соответственно. Эффект более значительной пассивации вакансий меди ближе к поверхности пленок CIGSe проявляется в уменьшении коэффициента $j$-shift (до 3.5 мэВ) для спектров ФЛ при возбуждении коротковолновым лазером (405 нм) с глубиной проникновения 30 нм по сравнению с лазерным возбуждением на длине волны 532 нм при глубине проникновения 100 нм. Пассивацией водородом приповерхностных слоев можно объяснить увеличение интенсивности полосы близкраевой люминесценции В-Т после облучения ионами водорода с энергией 2.5 кэВ. При такой энергии оценкой среднего количества первичных дефектов, расчитанного программой TRIM [26], созданных одним ионом водорода, является 2.5 , в то время как при энергии водорода 5 и 10 кэВ значение достигает 5 и 8 соответственно. Поэтому при энергии водорода 2.5 кэВ эффект пассивации превышает влияние созданных облучением радиационных дефектов, часть которых работает как безызлучательные ловушки носителей заряда.

Основываясь на энергетическом положении полос Р1 и Р2 по отношению к экспериментально установленному значению ширины запрещенной зоны $E_{g}$, можно оценить положение связанных с ними глубоких акцепторных уровней радиационно-индуцированных дефектов в запрещенной зоне твердых растворов CIGSe. Эти значения составили $\sim 0.25$ и 0.40 эВ для полос ФЛ $\mathrm{P} 1$ и $\mathrm{P} 2$ соответственно. Сопоставление полученных данных с известными теоретическими расчетами энергетических уровней дефектов в CIGSe позволяет сделать предположение о природе образующихся дефектов в тонких пленках при имплантации водорода [22]. Это могут быть атомы меди, замещающие индий, $\mathrm{Cu}_{\mathrm{In}}$, комплексы вакансий меди и селена, $V_{\mathrm{Cu}}-V_{\mathrm{Se}}$, или вакансии индия, $V_{\mathrm{In}}$.

\section{4. Заключение}

По данным рентгеноструктурного анализа установлено, что имплантация тонких пленок твердых растворов CIGSe ионами водорода $\mathrm{H}^{+}$в диапазоне энергий 2.5-10кэВ с дозой $3 \cdot 10^{15} \mathrm{~cm}^{-2}$ не меняет углового положения основных дифракционных рефлексов, а также их полуширины и соотношения интенсивностей. Определенные численные значения параметров элементарной ячейки составили $a \approx 5.738 \AA$ и $c \approx 11.45 \AA$. Математическая обработка СВЛ позволила определить значение ширины запрещенной зоны, $E_{g} \approx 1.171$ эВ при температуре жидкого гелия $\sim 4.2 \mathrm{~K}$, которое также оказалось не зависящим от условий имплантации пленок CIGSe. Обнаружено, что энергетическое положение полосы близкраевой люминесценции В-Т в спектрах ФЛ имплантированных ионами пленок CIGSe, снятых при возбуждении неравновесных носителей заряда лазерами с длинами волн $\sim 405$ и $\sim 532$ нм, сильно зависит от плотности мощности лазерного излучения с численным значением коэффициента $j$-shift $\sim 3.5$ и 8.4 мэВ соответственно. Различие эффекта пассивации основных легирующих акцепторов CIGSe, вакансий меди, атомами водорода объяснено различной глубиной проникновения лазерного излучения с длинами волн 405 и 532 нм. Пассивация осуществляется не только на поверхности, но и в объеме поликристаллических пленок на границах раздела зерен и дефектах структуры. 


\section{Финансирование работы}

Работа выполнена по проекту БРФФИ Ф20М-058, программе ГПНИ „Физическое материаловедение, новые материалы и технологии“, подпрограмма „Наноматериалы и нанотехнологии“ -2.56 , и государственного задания Министерства образования и науки России („Спин“ № AAAA-A18-118020290104-2).

\section{Конфликт интересов}

Авторы заявляют, что у них нет конфликта интересов.

\section{Список литературы}

[1] A. Polman, M. Knight, E.C. Garnett, B. Ehrler, W.C. Sinke. Science, 352 (6283), aad4424 (2016).

[2] M.A. Green, E.D. Dunlop, J. Hohl-Ebinger, M. Yoshita, N. Kopidakis, A.W.Y. Ho-Baillie. Progr. Photovolt.: Res. Appl., 28 (1), 3 (2020).

[3] T. Nishimura, S. Toki, H. Sugiura, N. Nakada, A. Yamada. Progr. Photovolt.: Res. Appl., 26 (4), 291 (2018).

[4] M.A. Contreras, L.M. Mansfield, B. Egaas, J. Li, M. Romero, R. Noufi, E. Rudiger-Voight, W. Mannstadt. Progr. Photovolt:: Res. Appl., 20 (7), 843 (2012).

[5] L.L. Kazmerskii. J. Electron Spectroscopy Relat. Phenomena, 150, 105 (2006).

[6] P. Jackson, D. Hariskos, R. Wuerz, W. Wischmann, M. Powalla. Phys. Status Solidi RRL, 8 (3), 219 (2014).

[7] P. Jackson, R. Wuerz, D. Hariskos, E. Lotter, W. Witte, M. Powalla. Phys. Status Solidi RRL, 10 (8), 583 (2016).

[8] M. Nakamura, K. Yamaguchi, Y. Kimoto, Y. Yasaki, T. Kato, H. Sugimoto. IEEE J. Photovolt., 9 (6), 1863 (2019).

[9] M. Imaizumi, T. Sumita, S. Kawakita, K. Aoyama, O. Ansawa, T. Aburaya, T. Hisamatsr, S. Matsuda. Progr. Photovolt.: Res. Appl., 13 (2), 93 (2005).

[10] K. Weinert, A. Jasenek, U. Rau. Thin Sol. Films, 431-432, 453 (2003).

[11] M.V. Yakushev, R.W. Martin, F. Urouhart, A.V. Mudryi, H.W. Schock, J. Krustok, R.D. Pilkington, A.E. Hill, R.D. Tomlinson. Jpn. J. Appl. Phys., 39, Suppl. 39-1, 320 (2000).

[12] M.V. Yakushev, R.W. Martin, J. Krustok, A.V. Mudryi, D. Holman, H.W. Schock, R.D. Pilkington, A.E. Hill, R.D. Tomlinson. Thin Sol. Films, 387 (1-2), 201 (2001).

[13] B. Dimmler, M. Powalla, H.W. Schock. Progr. Photovol.: Res. Appl., 10 (2), 149 (2002).

[14] A.V. Mudryi, V.F. Gremenok, A.V. Karotkii, V.B. Zalesskii, M.V. Yakushev,F. Lukkert, R. Martin. J. Appl. Spectroscopy, 77, 371 (2010).

[15] M.V. Yakushev, I.I. Ogorodnikov, V.A. Volkov, A.V. Mudryi. J. Vac. Sci. Technol., A29, 051201 (2011).

[16] D. Fink, J. Krauser, G. Lippold, M.V. Yakushev, R.D. Tomlinson, A. Weidinger, K.K. Dwivedi, S. Ghosh, W.H. Chung. Rad. Eff. Def. Solids, 145, 85 (1998).

[17] T. Tinoco, C. Rincon, M. Quintero, G. Sanchez Perez. Phys. Status Solidi A, 124 (2), 427 (1991).

[18] E.J. Friedrich, R. Fernandez-Ruiz, J.M. Merino, M. Leon. Powder Diffraction, 25, 253 (2010).

[19] A.P. Levanyuk, V.V. Osipov. Usp. Fis. Nauk, 133, 427 (1981).

[20] T. Gokmen, O. Gunawan, T.K. Todorov, D.B. Mitzi. Appl. Phys. Lett., 103 (10), 103506 (2013).
[21] F. Rong, G.D. Watkins. Phys. Rev. Lett., 58, 1486 (1987).

[22] M.V. Yakushev, J. Krustok, M. Grossberg, V.A. Volkov, A.V. Mudryi, R.W. Martin. J. Phys. D.: Appl. Phys., 49105108 (2016).

[23] R.D. Tomlinson, A.E. Hill, G.A. Stephens, M. Imanieh, P.A. Jones, R.D. Pilkington, P. Rimmer, M. Yakushev, H. Neumann. Proc. 11th E.C. Photovoltaic Solar Energy Conf. (Motreux, Switzerland, 1992) p. 791.

[24] M.V. Yakushev, R.D. Tomlinson, H. Neumann. Cryst. Res. Technol., 29 (1), 125 (1994).

[25] M.V. Yakushev, H. Neumann, R.D. Tomlinson, P. Rimmer, G. Lippold. Cryst. Res. Technol., 29 (3), 417 (1994).

[26] J.P. Biersack, L.G. Haggmark. Nucl. Instr. Meth., 174 (1-2), 257 (1980)

Редактор Л.В. Шаронова

\section{Radiative recombination on ion-induced defects in thin films of $\mathrm{Cu}(\mathrm{In}, \mathrm{Ga}) \mathrm{Se}_{2}$ solid solutions}

O.M. Borodavchenko ${ }^{1}$, V.D. Zhivulko ${ }^{1}$, A.V. Mudryi ${ }^{1}$, M.V. Yakushev ${ }^{2,3}$, I.A. Mogilnikov ${ }^{2}$

${ }^{1}$ Scientific-Practical Material Research Centre, National Academy of Sciences of Belarus, 220072 Minsk, Belarus

${ }^{2}$ Mikheev Institute of Metal Physics,

Ural Branch of Russian Academy of Sciences, 620108 Ekaterinburg, Russia

${ }^{3}$ Ural Federal University,

620002 Ekaterinburg, Russia

Abstract In thin films of $\mathrm{Cu}(\mathrm{In}, \mathrm{Ga}) \mathrm{Se}_{2}$ solid solutions radiationinduced effects after irradiation with hydrogen ions with energies of $2.5,5$ and $10 \mathrm{keV}$ and dose of $\sim 3 \cdot 10^{15} \mathrm{~cm}^{-2}$ were studied. A comparative analysis of the optical characteristics of nonimplanted and implanted $\mathrm{Cu}(\mathrm{In}, \mathrm{Ga}) \mathrm{Se}_{2}$ thin films was carried out based on the measurements of photoluminescence spectra and luminescence excitation spectra at liquid helium temperature, $\sim 4.2 \mathrm{~K}$. The bandgap of $\mathrm{Cu}(\mathrm{In}, \mathrm{Ga}) \mathrm{Se}_{2}$ solid solutions determined as a result of the luminescence excitation spectra mathematical processing was $\sim 1.171 \mathrm{eV}$. The intense band with the maximum at $\sim 1.089 \mathrm{eV}$ was found in the photoluminescence spectra of non-implanted and hydrogen-implanted $\mathrm{Cu}(\mathrm{In}, \mathrm{Ga}) \mathrm{Se}_{2}$ thin films caused by the recombination of free electrons with holes localized in the tails of the valence band. It was established that appearance of intense broad bands in the photoluminescence spectra with maxima in the energy range of $\sim 0.92 \mathrm{eV}$ and $\sim 0.77 \mathrm{eV}$ is due to radiative recombination of nonequilibrium charge carriers at deep energy levels of acceptor type ion-induced defects formed in the bandgap of $\mathrm{Cu}(\mathrm{In}, \mathrm{Ga}) \mathrm{Se}_{2}$ solid solutions. The conditions for the appearance of the ionic passivation effect of dangling electronic bonds on the surface and in the bulk of $\mathrm{Cu}(\mathrm{In}, \mathrm{Ga}) \mathrm{Se}_{2}$ polycrystalline films, possible nature of point defects in the structure and the mechanisms of radiative recombination are discussed. 